\section{Commentary: Innovative implantation strategies to accommodate size mismatch in lobar lung transplant}

\author{
Usman Ahmad, MD, FACS
}

Shortage of transplantable organs continues to be the Achilles' heel of solid-organ transplantation, especially lung transplant. This problem is even more pronounced in Japan due to unique social and cultural values and resulting donation trends. ${ }^{1}$ To deal with organ shortage and offer lung transplant as a therapeutic option for patients with endstage lung disease, our Japanese colleagues have developed innovative surgical strategies. In this context, their experience with living-donor lobar transplant has been quite successful, with low donor morbidity and excellent recipient survival and graft function. ${ }^{2}$

Transplanting a single lobe into ipsilateral or contralateral pleural space poses its own unique challenges. The 2 major problems that arise in this situation include (1) mismatch of pleural space to graft size and (2) mismatch of hilar size and anatomic orientation. In this outstanding technical manuscript, Nakajima and colleagues ${ }^{3}$ from the Kyoto Thoracic Surgery group have described the strategies of dealing with the aforementioned mismatch in the outcomes of the various approaches.

In case of living-donor liver transplantation, the transplanted lobe is almost always the lower lobe, and preferably right lower lobe. In the first combination, right lower and left lower lobes are harvested from 2 separate donors and transplanted into the same recipient after performing bilateral pneumonectomy. This was the most commonly performed living donor lobar transplant procedure in their

From the Department of Cardiothoracic Surgery, Heart and Vascular Institute, Cleveland Clinic, Cleveland, Ohio.

The author reported no conflicts of interest.

The Journal policy requires editors and reviewers to disclose conflicts of interest and to decline handling or reviewing manuscripts for which they may have a conflict of interest. The editors and reviewers of this article have no conflicts of interest.

Received for publication July 27, 2020; revisions received July 27, 2020; accepted for publication July 31, 2020; available ahead of print Aug 11, 2020.

Address for reprints: Usman Ahmad, MD, FACS, Department of Cardiothoracic Surgery, Heart and Vascular Institute, Cleveland Clinic, Cleveland, OH 44195 (E-mail: ahmadu@ccf.org).

JTCVS Techniques 2020;3:398-9

2666-2507

Copyright (c) 2020 The Authors. Published by Elsevier Inc. on behalf of The American Association for Thoracic Surgery. This is an open access article under the CC BY-NCND license (http://creativecommons.org/licenses/by-nc-nd/4.0/).

https://doi.org/10.1016/j.xjtc.2020.07.032

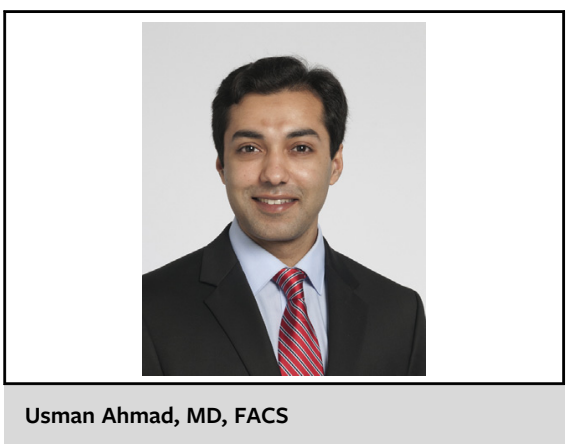

CENTRAL MESSAGE

Extreme size mismatch is a rela-

tive contraindication to trans-

plant. Lobar transplant and native upper lobe sparing strategies can

allow for accommodation of

pleural space to graft size

mismatch.

series. Among 47 patients, there were 4 events of bronchial complications, 1 30-day, and 2 in-hospital mortalities.

If the recipient's pleural space was significantly larger than the allograft lower lobe, the recipient upper lobe was left in situ and the donor lower lobe was transplanted after performing lower lobectomy or middle/lower bilobectomy. Another unique strategy was to take donor right lower lobe and implant into the left upper anatomic location in a heterotopic fashion. This is a technically challenging operation that requires extreme and meticulous attention to bronchial as well as vascular anastomoses. The pulmonary artery specifically takes a complex course, as it lies anterior and cephalad to the recipient bronchus, however, traverses posterior to the donor bronchus. In 22 patients transplanted using 1 of these 2 techniques, there was 1 in-hospital mortality. The third strategy was to transplant a single right lower lobe, which was performed in 11 patients. This group also suffered 1 in-hospital mortality.

From a functional standpoint, all 3 strategies appeared to result in adequate graft function with forced expiratory volume in 1 second ranging from $58 \%$ to $62 \%$ of predicted. Remarkable 5-year overall survival ranging from $75 \%$ to $90 \%$ was noted. Such excellent survival with good graft function is a testament to outstanding technical success as well as meticulous post-transplant care and follow-up.

Although European and North American programs are not as constrained in access to donor pool as Asian programs, expertise in lobar transplant can be helpful in 
managing extreme size mismatch. ${ }^{4}$ These strategies can be used for recipients whose donor pool is limited secondary to size and immunologic constraints and also in pediatric lung transplant procedures.

\section{References}

1. Date H. Current status and problems of lung transplantation in Japan. J Thorac Dis. 2016;8(suppl 8):S631-6.
2. Date H, Aoyama A, Hijiya K, Motoyama H, Handa T, Kinoshita H, et al Outcomes of various transplant procedures (single, sparing, inverted) in living-donor lobar lung transplantation. J Thorac Cardiovasc Surg. 2017; 153:479-86.

3. Nakajima D, Tanaka S, Ohsumi A, Date H. Outcomes of novel surgical procedures for graft size mismatch in living-donor lobar lung transplantation. J Thorac Cardiovasc Surg Tech. 2020;3:388-91.

4. Starnes VA, Barr ML, Cohen RG. Lobar transplantation. Indications, technique, and outcome. J Thorac Cardiovasc Surg. 1994;108:403-10. 